\title{
Concentrations of lead, cadmium and zinc in the tissues of reproductive organs of men
}

\author{
N. B. Oldereid ${ }^{1}$, Y. Thomassen ${ }^{2}$, A. Attramadal ${ }^{1}$, B. Olaisen $^{3}$ and \\ K. Purvis ${ }^{{ }^{*}}$ \\ ${ }^{1}$ Andrology Laboratory, Institute of Pathology, The National Hospital, Oslo, Norway; \\ ${ }^{2}$ National Institute of Occupational Health, Oslo, Norway; and ${ }^{3}$ Institute of Forensic Medicine, \\ The National Hospital, Oslo, Norway
}

\begin{abstract}
The concentrations of lead in blood and the concentrations of lead, cadmium and zinc in tissues were determined in various reproductive organs, liver and kidney removed at necropsy from 41 men who had died suddenly. None of the reproductive organs specifically accumulated lead and no significant correlation could be demonstrated between blood and organ concentrations or between concentrations and age, occupation or urban/rural background of the subject. Unlike lead, the tissue concentrations of cadmium increased with increasing age in all of the reproductive organs examined. Of these, the epididymides and seminal vesicles contained the highest concentrations. Whereas prostatic zinc also exhibited a significant age-dependent increase, the concentrations in the testes declined with age. The age-dependent increase in testicular cadmium did not become apparent until after the fourth decade, when any potentially deleterious impact on male fertility has less relevance. It is concluded that measurable amounts of lead and cadmium are present in all of the human reproductive organs but their organ and age distributions do not offer strong support for their involvement in the aetiology of male infertility or in the genesis of glandular neoplasms.
\end{abstract}

\section{Introduction}

The involvement of heavy metals in the aetiology of reproductive pathology, including prostatic cancer, has been debated for almost four decades. Specific metals, including lead and cadmium, have at different times been implicated in the aetiology of male infertility (Lancranjan et al., 1975; Thomas and Brogan, 1983; Schrag and Dixon, 1985), but the information has been partly anecdotal (Gilfillan, 1965) or based on animal models (Danielsson et al., 1984). Recent reports of a decrease in sperm quality in the general male population over the last five decades (Carlsen et al., 1992), which has also been reported over the last two decades in Norway (Bendvold, 1989), have added new impetus to the search for environmental agents and pollutants, such as the heavy metals, which can explain these alterations. Despite their potential reproductive significance, there are few studies on the capacity of the different human reproductive organs to accumulate these metals. This is especially important with regard to the prostate gland which is known to accumulate certain metals such as zinc (Leissner et al., 1980).

The aim of the present study was to determine the concentrations of lead, cadmium and zinc in the tissues of different reproductive organs of men after necropsy and to evaluate the extent to which these are influenced by age, occupation and urban and rural environments.

${ }^{*}$ Correspondence.

Received 12 November 1992.

\section{Materials and Methods}

\section{Subjects}

Organs were removed at necropsy from 41 men (median age 40 years, range $18-80$ ) who had died suddenly. All had undergone routine autopsy at the Institute of Forensic Medicine, The National Hospital, Oslo, during the period March to June 1988. Subjects with suspected alcohol and drug abuse were excluded from the study. Tissue samples were collected from the liver, kidney, testes, prostate gland, epididymides and seminal vesicles within 2 days of death. After the samples were dissected free from fat and superficial connective tissue, they were transferred to $-20^{\circ} \mathrm{C}$ and stored until the day of assay. In addition, a blood sample $(10 \mathrm{ml})$ was collected from each subject in a heparinized tube and stored at $-20^{\circ} \mathrm{C}$. Information regarding the age, place of residence and occupation of the subjects was obtained from the register at the Institute of Forensic Medicine and, where necessary, the local police authorities. Comparisons were made between men with rural $(n=14)$ and urban ( $n=25$ ) backgrounds. Rural backgrounds were defined as residential areas with a population of less than 250000 inhabitants. Occupations were divided according to their potential level of exposure to environmental pollutants. Only data from high risk ( $n=10$; all forms of industrial, construction and transport work) and low risk occupations $(n=10$; office and administrative work, teaching profession) were compared. 


\section{Samples and sample preparation}

After thawing, all tissue samples were freeze-dried in a standard laboratory system. Tissues (approximately $0.5 \mathrm{~g}$ ) were digested with $5 \mathrm{ml}$ concentrated nitric acid and then heated for $1 \mathrm{~h}$ at $85^{\circ} \mathrm{C}$ in Teflon tubes. The resulting solution was then diluted with water up to $25 \mathrm{ml}$. After thawing, the whole blood samples were diluted $1: 5$ with a solution containing $0.5 \%$ $\mathrm{NH}_{4} \mathrm{H}_{2} \mathrm{PO}_{4}$ and $0.5 \%$ Triton X-100.

The following certified tissue reference materials were also processed: NIST SRM 1577 bovine liver (National Institute of Standards and Technology, Gaithersburg, MD) and IAEA H-4 animal muscle (International Atomic Energy Agency, Vienna). Whole blood quality control materials were obtained from Nycomed Ltd (Oslo).

\section{Measurement of lead, cadmium and zinc}

Cadmium and lead were measured by electrothermal atomic absorption spectrometry. A Perkin-Elmer 5100 atomic absorption spectrophotometer equipped with a Zeeman-effect based background corrector, a HGA-600 graphite atomizer, an AS-60 automatic sampler and Perkin-Elmer electrode discharge lamps were used. Chemical modification was carried out with palladium nitrate and calibration was performed against aqueous solutions. Zinc was measured by inductively coupled plasma atomic emission spectrometry using a sequential Perkin-Elmer 5500 spectrometer.

The accuracy of the techniques was monitored by measurement of certified reference materials and the average concentrations found for cadmium, lead and zinc in these materials were within $\pm 10 \%$ of the certified values. The detection limit for lead in whole blood was $0.05 \mu \mathrm{mol} \mathrm{l}^{-1}$. The detection limits for cadmium, lead and zinc $\left(0.3 \mathrm{~g}^{-1}\right.$ dry weight) were $0.01,0.08$ and $0.1 \mu \mathrm{g} \mathrm{g}^{-1}$, respectively.

\section{Statistical analysis}

The data were compared after logarithmic transformation by Student's $t$ test for unpaired observations, correlation analysis and linear regression using a statistical package (Statgraphics).

\section{Results}

\section{Lead}

Lead was detected in the blood and reproductive organs of all of the 41 subjects examined (Table 1). The concentrations of lead accumulated in the liver and kidney were approximately five times greater than in the reproductive organs, none of which exhibited a special capacity for concentrating the metal. Although the average concentrations of lead in blood tended to be higher in men from an urban background (geometric mean and 95\% confidence interval: $0.49 \mu \mathrm{mol} \mathrm{l}^{-1}, 0.40-0.60 \mu \mathrm{mol} \mathrm{l}^{-1}$, respectively) compared with those from rural areas $\left(0.33 \mu \mathrm{mol}^{-1}\right.$ $0.26-0.42 \mu \mathrm{mol} l^{-1}$, respectively), this difference was not statistically significant. Moreover, no difference could be demonstrated between the rural and urban groups with regard
Table 1. Concentrations ( $\mu \mathrm{g} \mathrm{g}^{-1}$ dry weight) of lead, cadmium and zinc in reproductive organs, liver and kidney of men

\begin{tabular}{lccc}
\hline Organ & Lead & Cadmium & Zinc \\
\hline Testes & 0.16 & 0.56 & 74.6 \\
& $(0.13-0.19)$ & $(0.45-0.71)$ & $(71.3-78.0)$ \\
Epididymides & 0.18 & 0.97 & 92.3 \\
& $(0.15-0.22)$ & $(0.72-1.32)$ & $(78.9-108.1)$ \\
Prostate gland & 0.15 & 0.63 & 679 \\
& $(0.12-0.20)$ & $(0.48-0.83)$ & $(540-839)$ \\
Seminal vesicles & 0.15 & 0.71 & 102 \\
& $(0.12-0.18)$ & $(0.54-0.93)$ & $(93-111)$ \\
Kidney & 0.70 & 93.7 & 182 \\
& $(0.60-0.82)$ & $(72.2-121.6)$ & $(168-198)$ \\
Liver & 0.86 & 4.06 & 216 \\
& $(0.71-1.05)$ & $(3.23-5.04)$ & $(189-250)$ \\
\hline
\end{tabular}

Table 2. Regression analysis of age-related changes in the concentrations ( $\mu \mathrm{g} \mathrm{g}^{-1}$ dry weight) of lead, cadmium and zinc in reproductive organs, liver and kidney of men

\begin{tabular}{llcc}
\hline Organ & Cadmium & Lead & Zinc \\
\hline Testes & $0.56^{* * *}$ & -0.29 & $-0.38^{*}$ \\
Epididymides & $0.49^{* *}$ & -0.15 & -0.19 \\
Prostate gland & $0.62^{* * *}$ & -0.05 & $0.41^{* *}$ \\
Seminal vesicles & $0.50^{* *}$ & -0.17 & -0.16 \\
Kidney & $0.38^{*}$ & -0.23 & 0.25 \\
Liver & 0.25 & -0.30 & -0.27 \\
\hline
\end{tabular}

Values given are correlation coefficients.

${ }^{*} P<0.05 ;{ }^{* *} P<0.01 ;{ }^{* * *} P<0.001$.

to the concentrations of lead in tissues of any of the reproductive organs (data not shown). Neither the age (Table 2) nor the occupation (data not shown) of the subjects appeared to influence the tissue or blood concentrations of lead. No correlation could be demonstrated between the concentrations of lead in blood and the concentration of lead in any of the tissues examined, including liver and kidney.

The concentrations of lead in liver and kidney tissue were highly correlated $(P<0.001 ; r=0.67)$ and a significant positive correlation was also detected between the concentrations of lead in the liver and epididymides $(P<0.001 ; r=0.41)$.

\section{Cadmium}

Cadmium could be detected in all of the tissues examined with the highest concentrations in kidney tissue (Table 1). Of the reproductive organs, the epididymides accumulated significantly greater quantities of cadmium than did the prostate Downloaded from Bioscientifica.com at 04/26/2023 08:03:15AM 

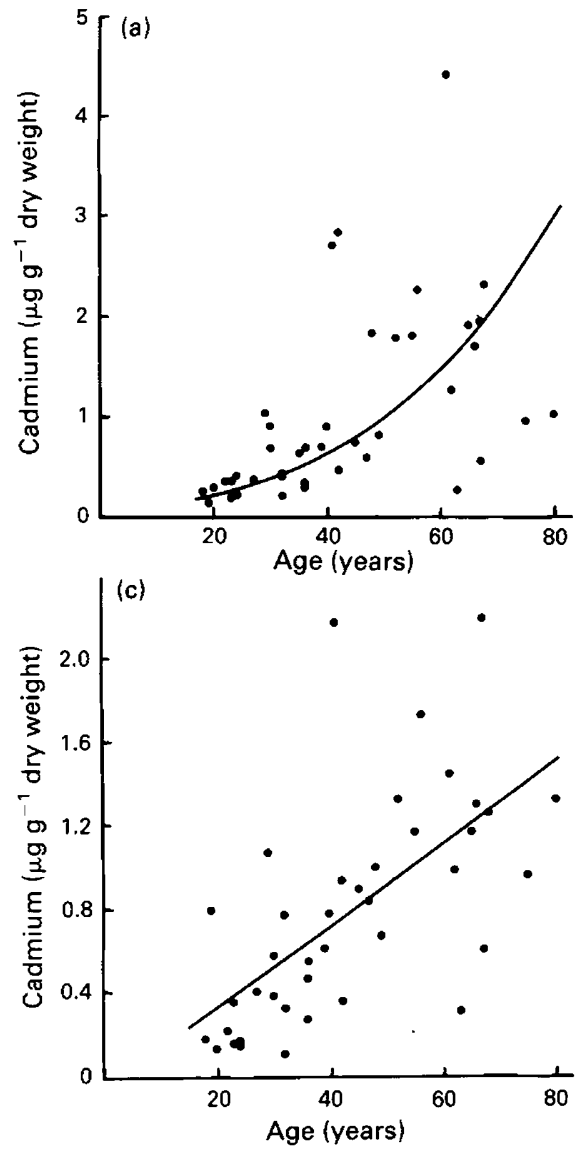

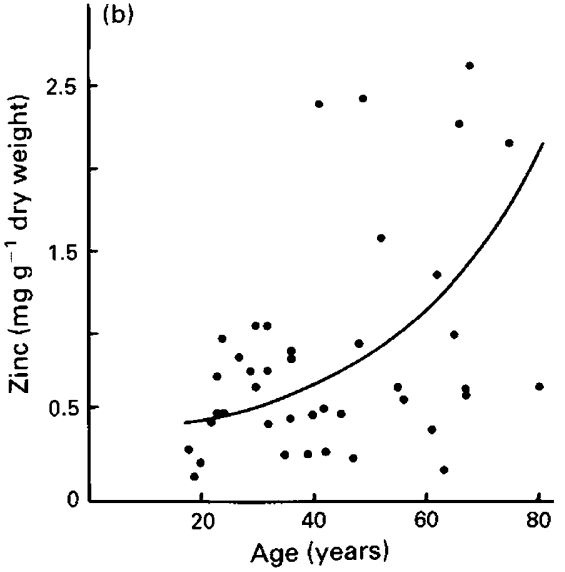

Age (years)

Fig. 1. Age-dependent changes in the concentration of cadmium ( $\mu g g^{-1}$ dry weight) in (a) human seminal vesicles and (c) prostate glands and (b) zinc ( $\mathrm{mg} \mathrm{g}^{-1}$ dry weight) in prostate glands removed at necropsy from 41 men after sudden death. The lines represent a linear regression (c) or best fit exponential curves $(a$ and $b$ ) created by a statistical program.
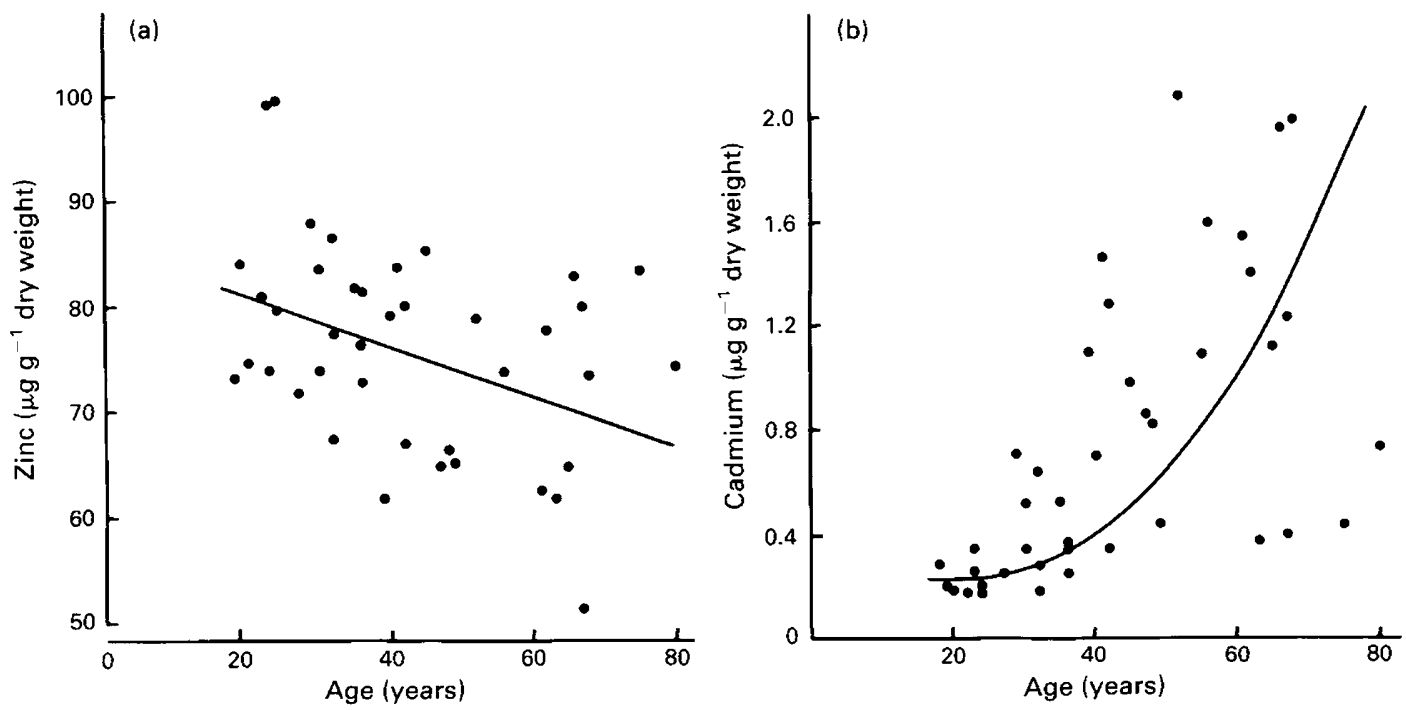

Fig. 2. Age-dependent changes in the concentration of (a) zinc and (b) cadmium ( $\mu \mathrm{g} \mathrm{g}^{-1}$ dry weight) in human testes removed at necropsy from $\mathbf{4 1}$ men after sudden death. Lines represent linear regression (a) or best fit exponential curve (b). 
gland $(P<0.05)$ and testis $(P<0.01$; Table 1$)$. The concentrations of cadmium in kidneys were positively correlated with its concentrations in the seminal vesicles $(P<0.05 ; r=0.33)$ and epididymides $(P<0.01 ; r=0.40)$. The concentrations in liver were also positively correlated with the concentrations of cadmium in the same organs $(P<0.02 ; r=0.38$ and $P<0.001 ; r=0.55$ for seminal vesicles and epididymides, respectively). No significant association was found between concentrations of cadmium in liver and kidney. All of the reproductive organs, and to a lesser extent the kidney, exhibited an age-dependent increase in concentrations of cadmium in tissues (Table 2; Fig. 1). The amount of cadmium in the tissues was not influenced by the rural or urban backgrounds of the subjects or their occupation (data not shown).

\section{Interaction with zinc}

The highest concentrations of zinc were associated with the prostate gland $(P<0.001$ compared with the other reproductive organs) and concentrations of zinc in the prostate gland increased with the age of the subject (Fig. 1; Table 2). A significant positive correlation was seen between the prostatic zinc and cadmium concentrations $(P<0.02 ; r=0.37)$, but not with lead in the same organ. No correlation was demonstrated between any of the organs, including liver and kidney, with regard to zinc concentrations. Testicular zinc underwent a significant reduction in concentration with increasing age (Table 2; Fig. 2).

\section{Discussion}

The study reported here indicated that the human reproductive organs contain cadmium and lead in various concentrations. The concentrations of cadmium and zinc in the prostate gland are in close agreement with previously published values (Lahtonen, 1985; Lindegaard et al., 1990). Although cadmium has been implicated in the aetiology of prostatic cancer (Kipling and Waterhouse, 1967; Waalkes ef al., 1989), in the present study, no clear prostate-specific concentration of cadmium could be demonstrated. Indeed, the epididymides, and to a lesser extent the seminal vesicles, appeared to be more efficient than both the prostate gland and testis in their capacity to accumulate cadmium. Cancer of the epididymis and seminal vesicles is extremely rare (The Cancer Registry of Norway, 1990). Furthermore, several reports indicate that zinc can protect various tissues against the toxic and carcinogenic effects of cadmium (Koizumi and Waalkes, 1989; Saxena et al., 1989; Wahba and Waalkes, 1990). If these proposed antagonistic effects of zinc on cadmium are correct, it would be expected that the high concentrations of zinc in the human prostate, which also increase with age, would tend to exert an increasingly protective action within the gland, assuming they share a common anatomical and cellular distribution. This would further weaken the postulated association between cadmium and prostatic cancer.

Several reports have demonstrated that cadmium is highly toxic in the testis and epididymis (see review by Elinder, 1986). One pathological mechanism which has been proposed is through an antagonism of zinc (Saxena et al., 1989). It may be relevant in this respect that the testicular concentrations of zinc decrease inversely with the rise in tissue cadmium with age. However, the age-related rise in tissue cadmium in the testes and other organs was most apparent after the fourth decade, a time when any potentially negative influence on spermatogenesis has decreasing relevance. However, it is acknowledged that from the fourth decade, human Leydig cell function begins to decline independently of hypophyseal function (Davidson et al., 1983; Deslypere and Vermeulen, 1984). The possibility that an age-dependent accumulation of cadmium in the testis can contribute to this reduction in steroidogenic function should be investigated.

Information regarding the smoking habits of the subjects was not available and it is ackowledged.that smoking increases the concentrations of cadmium in blood and in seminal plasma (Saaranen et al., 1989), and this may explain some of the variability in the extent to which the metal accumulates in the reproductive tissues with age.

Lead is known to impair spermatogenic function (Lancranjan, 1975; Cullen et al., 1984; Assennato et al., 1987) and in animal models displays marked testicular toxicity (Chowdhury et al., 1984). In the study presented here, no differences could be demonstrated between the different reproductive organs with regard to their capacity for accumulating lead, which was generally at a low level. Unlike cadmium, tissue concentrations of lead were not altered with increasing age. Furthermore, the concentrations of lead in the systemic circulation could not be clearly related to the age, the urban/rural environments or to the occupation of the subject. However, it should be emphasized that these results are only relevant for the level of environmental pollution found in Norway. In countries with less stringent environmental regulations, the extent to which occupation and geographical factors influence the amounts of lead and cadmium in tissues may be more evident.

In summary, the involvement of lead and cadmium in the aetiology of reproductive pathology is still controversial. The results of the present study cast doubt on the involvement of cadmium in prostate carcinogenesis, unless the organ has a specific sensitivity to the metal. They also decrease the possibility that the observed decline in number of spermatozoa in the general population (Carlsen et al., 1992) can be explained by the accumulation of lead and cadmium in the testes.

N. B. Oldereid would like to acknowledge financial support for this study from Dr Alexander Malthe's legacy. Economic support was also provided by Statoil Norway Ltd.

\section{References}

Assennato G, Paci C, Baser ME, Molinini R, Candela RG, Altamura BM and Giorgino R (1987) Sperm count suppression without endocrine dysfunction in lead-exposed men Archives of Environmental Health 42 124-127

Bendvold E (1989) Semen quality in Norwegian men over a 20 -year period International Journal of Fertility 34 401-404

Carlsen E, Giwercman A, Keiding N and Skakkebæk N (1992) Evidence for decreasing quality of semen during past 50 years British Medical Journal 305 $609-613$

Chowdhury AR, Dewan A and Gandhi DN (1984) Toxic effect of lead on the testis of rat Biomedica et Biochimica Acta 1 95-100

Cullen MR, Kayne RD and Robins JM (1984) Endocrine and reproductive dysfunction in men associated with occupational inorganic lead intoxication Archives of Environmental Health 39 431-440

Downloaded from Bioscientifica.com at 04/26/2023 08:03:15AM 
Danielsson BRG, Dencker L, Lindgren A and Tjälve H (1984) Accumulation of toxic metals in male reproduction organs Archives of Toxicology Supplement 7 $177-180$

Davidson JM, Chen JJ, Crapo L, Gray GD, Greenleaf WJ and Catania JA (1983) Hormonal changes and sexual function in aging men journal of Clinical Endocrinology and Metabolism 57 71-77

Deslypere IP and Vermeulen A (1984) Leydig cell function in normal men: effect of age, life-style, residence, diet, and activity Journal of Clinical Endocrinology and Metabolism 59 955-962

Elinder CG (1986) Other toxic effects. In Cadmium and Health: A Toxicological and Epidemiological Appraisal, Vol. 2 pp 159-204 Eds L Friberg, CG Elinder and T Kjellström. CRC Press, Boca Raton

Gilfillan SC (1965) Lead poisoning and the fall of Rome Journal of Occupational Medicine $753-60$

Kipling MD and Waterhouse JAH (1967) Cadmium and prostatic carcinoma Lancet i 730-731

Koizumi T and Waalkes MP (1989) Effects of zinc on the distribution and toxicity of cadmium in isolated interstitial cells of the rat testis Toxicology 56 137-146

Lahtonen R (1985) Zinc and cadmium concentration in whole tissue and in separated epithelium and stroma from human benign prostatic hypertrophic glands The Prostate 6 177-183

Lancranjan I, Popescu HI, Gavanescu O, Klepsch I and Serbanescu M (1975) Reproductive ability of workmen occupationally exposed to lead Archives of Environmental Health 30 396-401
Leissner KH, Fjelkegard B and Tisell LE (1980) Concentration and content of zinc in the human prostate Investigative Urology 18 32-39

Lindegaard PM, Hansen SO, Christensen JEJ, Andersen BB and Andersen O (1990) The distribution of cadmium within the human prostate Biological Trace Element Research 25 97-104

Saaranen M, Kantola M, Saarikoski S and Vanha-Perttula T (1989) Human seminal plasma cadmium: comparison with fertility and smoking habits Andrologia 21 140-145

Saxena DK, Murthy RC. Singh C and Chandra SV (1989) Zinc protects testicular injury induced by concurrent exposure to cadmium and lead in rats Research Communications in Chemical Pathology and Pharmacology 64 317-329

Schrag SD and Dixon RL (1985) Occupational exposures associated with male reproductive dysfunction Annual Review of Pharmacology and Toxicology 25 $567-592$

The Cancer Registry of Norway (1990) The Incidence of Cancer in Nonway, 1990. The Norwegian Cancer Society, Oslo

Thomas JA and Brogan WC (1983) Some actions of lead on the sperm and on the male reproductive system American Joumal of Industrial Medicine 4 127-183

Waalkes MP, Perantoni A and Rehm S (1989) Tissue susceptibility factors in cadmium carcinogenesis: correlation between cadmium-induction of prostatic tumours in rats and an apparent deficiency of metallothionein Biological Trace Element Research 21 483-490

Wahba ZZ and Waalkes MP (1990) Effect of in vivo low-dose cadmium pretreatment on the in vitro interactions of cadmium with isolated interstital cells of the rat testes Fundamental and Applied Toxicology $15641-650$ 